\title{
Enacting Homebirth Bodies: Midwifery Techniques in Germany
}

\author{
Annekatrin Skeide ${ }^{1}$
}

\begin{abstract}
Building on insights from science and technology studies-inspired anthropological research on reproduction, this paper uses a praxiographic approach to analyze homebirth midwifery practices in Germany. I show that such practices are syncretic, and that techniques of routinizing and multiplying obstetrical interventions are combined in more or less coherent ways to configure pregnancies and births as physical, emotional, and social becomings. In the process of attending, homebirth bodies learn to co-respond to each other, to the midwifery techniques, and to the homebirth environment. Understanding how and with which aims midwives and women invest in those longterm engagements specific to homebirth surroundings may inform clinical practices.
\end{abstract}

Keywords Midwifery · Homebirth · Bodies · Practices · Techniques · Germany

\section{Introduction}

Women are able to give birth! We as midwives know that-still. Midwives know that women have the capacities to give birth qua nature [von Natur aus]. And they trust in [women's] success. Because midwives know that a spontaneous birthing process [spontaner Geburtsverlauf] cannot be improved. Obstetricians tend to consider birth as something that can be made safer with the help of technological interventions than it would be without those

Annekatrin Skeide

A.Skeide@uva.nl

1 Anthropology Department, Amsterdam Institute for Social Science Research (AISSR),

University of Amsterdam, Amsterdam, The Netherlands 
interventions. The dominance of the medical concept of risk has led to high intervention rates and to increasingly pathologizing an originally healthy and natural vital process.

- Martina Klenk, President of the German Association for Midwives

At the triennial conference for midwives in 2016, Martina Klenk, then President of the German Association for Midwives (Deutscher Hebammenverband), to which the majority of German midwives are affiliated, proclaimed a programmatic position for midwifery in Germany. She warned against an obstetric-technological authority redefining birth as essentially risky and marginalizing midwives, who, by contrast, simply allow 'natural' birth to happen. Klenk voiced a common juxtaposition: obstetricians argue for prioritizing the medical surveillance of and (intervention into) the corporeal changes that pregnancy, birthing, and postpartum stages bring, while midwives emphasize that those events form a 'normal' or 'natural' life phase, a definition that infers "both a task and a way of belonging for midwifery, a profoundly normative claim" (Weir 2006:79). The German "Law for Midwives" (Hebammengesetz [HebG] 2016 [1985], Sect. 5) sets forth these tasks that are also a claim: midwives are trained "to give advice to women in pregnancy, during birth, and the postpartum phase; to provide the care necessary; to guide normal birth; to recognize any complication during birth early on; to take care of neonates; to surveil the postpartum period; and to document the course of birth."

Giving advice, providing care, monitoring, and diagnosing are, however, activities that midwives share with their medical colleagues. As the German healthcare landscape is dominated by obstetric care, it is difficult for midwives to find their niche: irrespective of whether women (and children) are actually in need of obstetric treatment, most women are attended to by gynecologists and obstetricians during pregnancy. Then they give birth in hospitals. On clinical labor wards they are accompanied by both midwives and obstetricians, but obstetricians are the ones in charge.

That birth in Germany is a 'medicalized event' is also indicated by the high cesarean section rates (greater than $30 \%$ in 2015), twice as high as those assessed in Finland or Norway, for comparison (Stone 2012; OECD 2018). German midwives provide nonclinical assistance during birth and accompany women independently from obstetricians and throughout the whole trajectory, including pregnancy, birthing, and postpartum stages. But this is decreasingly the case: in 2015 it was estimated that in Germany no more than $1.3 \%$ of all births took place outside the hospital (QUAG 2016:9) ${ }^{1}$; in comparison, 30\% of all births in the Netherlands were extra-clinical (Scarf et al. 2018:241).

Discourses that juxtapose obstetrics and midwifery easily camouflage that in practice, the tasks, approaches, and responsibilities of midwives and obstetricians overlap, and their respective remits are less well defined, as is repeatedly suggested (see for example Cheyney 2011; Rothman 2012). I therefore propose to understand midwifery care neither as a counterpoint nor as an accessory to obstetric care, but as a set of practices in which different interventions and ideals are combined in ways that fit

\footnotetext{
1 In Germany, homebirths might become even rarer in the near future. There are fewer and fewer midwives offering those services, as indemnity insurance costs for nonclinical birth are constantly rising and therefore attending homebirths has become unaffordable for many midwives (DHV 2014:5).
} 
the environment in which midwives attend women and their children, partners, and families during pregnancy, birth, and the weeks and months following birth.

In this paper, I suggest revising the discursive position that designates midwives as being in charge of 'natural' or physiological births, in opposition to obstetricians who deal with pathological births; the practical realities of midwifery care emerge from a syncretic combination of repertoires that are informed by both discourses, creating a sociotechnical practice of skilled midwifery. I argue that it is important for midwives, and the women, children, and families they attend to, not to conjure the notion of a 'natural' birth, thus insinuating that giving birth is an innate physical event that requires as little intervention as possible, since this makes invisible both the work that needs to be done for giving birth, and the environment in which certain skills and knowledge repertoires are indispensable. Instead, I suggest concentrating on the specificities of midwifery practices in order to improve the understanding of what they actually involve. Against the backdrop of contested "global and local politics of birth" (Chadwick 2018:3), encompassing rising obstetric intervention rates all over the globe as well as high rates of perinatal deaths of women and children in 'Southern' parts of the world (de Kok, Hussein, and Jeffery 2010:1703), midwives and women could position themselves more strongly in relation to midwifery care and the alternatives articulated therein, particularly regarding births at home and in homelike environments.

\section{Anthropological Background}

Martina Klenk argues for a certain midwifery culture that allows 'natural' birth "to run its course" (Aune et al. 2017:21). In her conceptualization of 'natural' birth she stages birthing bodies as needing undisturbed-equated to un-technological and unmedical-surroundings in order for their 'natural' potential to unfold. Conceiving bodies as not only naturally universal, as suggested by midwifery discourses, but also as socioculturally specific, is done in anthropological inquiries of reproduction whose starting point is marked by Brigitte Jordan's 1978 ethnography Birth in Four Cultures (MacCormack 1996:96). Jordan ([1978] 1993:3) states that birth is an universal event that is "everywhere socially marked and shaped." This sociocultural notion of birth has been taken up fruitfully, resulting in a rich corpus of intercultural comparisons of birth practices (MacCormack 1982; Kay 1982; De Vries et al. 2001; Davis-Floyd, Sargent, and Rapp 1997). In early works in particular, 'modern' obstetrics were vehemently criticized for disrupting "viable, healthy and culturally embedded indigenous systems" (Davis-Floyd, Sargent, and Rapp 1997:5), an idea that has also informed research questions of studies undertaken in so-called Western countries (Oakley 1984; Petchesky 1987; Davis-Floyd 1992; Barker 1998). 'Western', and more precisely American, obstetrics have been shown for producing medicalized or "technocratic bodies" (Davis-Floyd 1994). Similarly to bodies in "traditional non-Western birthing system[s]" (Macdonald 2006:239), bodies giving birth in non-clinical midwife-led environments in the US have been conceived as 'natural', knowing, and self-sufficient (Davis-Floyd 1992; Rothman 1982; Kitzinger 
1979, 2011; Cheyney 2008, 2011; Davis-Floyd and Davis 1996; Simonds, Rothman, and Norman 2007).

Conceiving of births and birthing bodies as either belonging to a midwifery model that figures as natural or physiological, or to the medical model that makes giving birth risky if not pathological (Rooks 1999, 370-71), not only keeps social and technological practices separate from one another, but also situates birth within birthing bodies. In this paper, I seek to pay attention to birthing bodies' physicalities without essentializing them or making them universal, but instead by situating birthing bodies in specific social and technological practices. To do so, I build on insights from science and technology studies (STS)-inspired anthropological research on new reproductive technologies. Anthropological scholars engaged with STS in order to account for the birth of the first child produced by in vitro fertilization, Louise Brown. ${ }^{2}$ They were and are still interested in studying new technologies' impacts not only on human reproduction but also on classical binary categories, such as nature-culture ${ }^{3}$ or, indeed, human-nonhuman, as well as on many domains of social life (Inhorn and Birenbaum-Carmeli 2008:178), including kinship and gender (Franklin 2013; Inhorn et al. 2017; Culley and Hudson 2009; Strathern 1992; Ram and Jolly 1998; Rapp 2000; Thompson 2005).

Including technologies in non-binary ways in their analysis is also what Madeleine Akrich and Bernike Pasveer have done in their studies of obstetrical practices, which combine anthropology with STS. They argue that " '[n]atural' birth is not something that occurs all by itself" (Pasveer and Akrich 2001:236) but is a sociotechnical achievement. Their work shows that homebirth bodies are neither pre-existent nor unchangeable, and that their emergences are, among others, mediated by technical devices (Akrich and Pasveer 2004:64-65). I especially take inspiration from Akrich and Pasveer's work on obstetrical monitoring technologies that coordinate obstetrical practices and their participants with each other and with the system or 'paradigm' of Obstetrics. In this way, Akrich and Pasveer argue, technologies of surveillance multiply their objects-fetuses among others-and thereby also what Obstetrics are (Akrich and Pasveer 2000). Following Akrich and Pasveer (2000:65), I would like to argue that interventions aimed at surveilling women and children, which midwifery shares with obstetrics, are not "static and monolithic" but are combined with other interventions and ideals in midwifery practices, ${ }^{4}$ and are thereby transformed into midwifery techniques. ${ }^{5}$ Considering that objects of obstetric technologies differ from one practice to another (Akrich and

\footnotetext{
${ }^{2}$ Louise Brown was born in 1978, the same year of the above-mentioned publication by Jordan on birth as a cultural phenomenon.

3 Marilyn Strathern contributed mainly to a critical reflexive approach to the 'natural'-in contrast to the 'cultural' - as particular Western categories and as a particular Western way of making sense through (re)producing assemblages of contrasts (Strathern 1995:177).

4 In taking practices as the focus of analysis, I follow feminist STS researchers Annemarie Mol (2014), Jeannette Pols (2017), Ingunn Moser (2011), Annelieke Driessen (2017), Else Vogel (2017), Willemijn Krebbekx (2018), and Amade M'Charek (2013).

5 In their recent publication, Elizabeth Newnham, Lois McKellar and Jan Pincombe (2018) use a similar concept, namely "midwifery technologies." But whereas Newnham et al. use "midwifery technologies" in opposition to "medical birth technologies" (Newnham, McKellar, and Pincombe 2018:82), I use "midwifery techniques" in order to describe ways of combining syncretic midwifery practices.
} 
Pasveer 2000:70), I show how women's (and midwives') bodies are shaped by midwifery techniques in homebirth environments. I give answers to following questions: What techniques do midwives and women use in homebirth practices in order to make homebirth work? Which homebirth bodies emerge from those midwifery attendance techniques?

\section{Studying Midwifery Practices: A Praxiographic Approach}

The findings I present are based on praxiographic fieldwork (Mol 2002) conducted between February 2015 and March 2016 in most of the various settings in which midwives in Germany work. Interested in their care practices (Mol, Moser, and Pols 2010:7-11), I accompanied midwives in birthing centers, hospitals, and people's homes as they took care of women, children, and families during pregnancy, during birth, and during the weeks and month after birth. In addition to participant observation, I conducted twenty semistructured interviews with the women and midwives I accompanied. These interviews were initiated by asking my interviewees to describe in their own terms a particular attendance situation in which we had both participated.

The praxiographic position I take allows for considering materialities and techniques, in this case those that are involved in homebirth midwifery practices and that allow for bringing homebirth bodies into being. The aim is to present complex situations in which social and material entities and events are not separated. In order to do so, it is necessary to decide not only who (women, children, partners, midwives) but also what (things, ideals, words, bodies) is part of the situation in which ways. Homebirth bodies are not presumed to precede the practices of giving birth in which they are involved, but they are enacted in those practices in specific ways.

For mapping out midwifery practices that are specific to the environments in which they take place, I moved between different sites and care phases in order to draw out similarities and contrasts of "local knowledges" (Marcus 1995:111). The midwifery practices that I describe are situated: they are related to specific times and spaces; to the women and midwives I encountered; to the German healthcare system; and not least to my own position as a researcher and a trained midwife. Engaging with different sites allowed me to discern overlapping and differing ways of attending births, to pay attention to overarching or recurring discourses, and to be sensitive to how these discourses relate to different practices. These sensitivities also inform this article, in which I focus on homebirth practices.

My focus on homebirth practices should not distract from the larger context in which, not only through sharing certain devices and techniques but also through partitioning tasks and responsibilities, homebirth practices are tightly associated with clinical birthing practices. 


\section{Midwifery Techniques: Routinizing and Multiplying Obstetrical Interventions}

Midwife Jana explains that when she started to provide homebirth assistance after her midwifery training ${ }^{6}$ she appreciated having received a "good medical training" that prepared her well. Like medical doctors in German spa (Kur) settings who provide orthodox medical remedies next to alternative therapies (Naraindas 2011), Jana emphasizes that she "expanded her repertoire" by taking courses in acupuncture and homeopathy, and using obstetrical as well as alternative diagnostics and therapies in her work. Jana's midwifery practices are syncretic as they combine different knowledge and skills in specific ways. But how do midwives do that? How are practices that do not necessarily cohere made to fit together (Law et al. 2014:177) in more or less coherent ways?

Midwife Julia illustrates the broad scope of the work done by midwives:

My work is quite diverse: I attend women during pregnancy, which means I am always there for them if they have questions, worries, or fears. But I also do prenatal screening, this specialist field. And I do births from A to Z. This means I attend to women at home or in the birthing place. And I also attend to couples in their being-parents. And I make sure that the baby and the mother and the father are well. I am a temporary friend, I do lactation counseling, I do nutrition counseling, I do partnership counseling, I do how-to-handle-yourmother-in-law counseling. So there is a lot more to it than just checking.

Julia makes clear that when accompanying women during pregnancy and birth, interventions carried out for surveilling pregnancy and birth ("I do prenatal screening. I do birth from A to Z." ) are important, even pivotal activities. However, they belong to "this specialist field" that midwifery shares with obstetrics, which is surveillance. She emphasizes that "there is a lot more" to her work "than just checking," a statement that decenters monitoring as the main activity in her homebirth attendance. Instead, monitoring is one of many other "diverse" activities: assuring women, assisting birth, accompanying 'becoming family', giving professional advice and becoming a "temporary friend" who is "always there." 7 According to Julia, "attending to" women, couples, and families encompasses taking care of the physical, emotional, and social dimensions of being pregnant, giving birth, and taking care of a newborn. "Checking" women's and children's physical state becomes merged into the multifaceted attendance repertoire Julia uses in order to configure pregnancy as a physical, emotional, and social becoming. Tina, who has been attended to by Julia during both of her pregnancies and births in the midwife-led birthing center and at home, appreciates how Julia handles the surveillance of her pregnancy:

\footnotetext{
6 The training of midwives is composed of two parts: practical units and theoretical courses. Practical units are located in hospitals for the most part. Central components of the theoretical courses are medical subjects such as gynecology, obstetrics, and pediatrics, commonly taught by medical doctors.

7 In homebirth practices, "always being there," as midwife Julia puts it, means concretely that women can contact midwives any time if they have "questions, worries, or fears."
} 
What I like about Julia is that she ... focuses on how I feel: "If you feel well then usually your child is well, too." And she still checks urine and blood values where you can also find out a lot. You can have a relaxed pregnancy. You don't have to worry too much even if the urine is perhaps not so good sometimes.

While Tina knows well the screening procedures and what they aim at, she is not supposed to "worry too much" about the results as they generally do not affect her pregnancy. Tina can be "relaxed" because her midwife guides her in focusing on how she feels, while Julia assumes the tasks of evaluating the measurements and acting upon them if necessary. Tina's statement shows that this is a mutual, codependent endeavor: she needs to collaborate by following Julia's guidance to focus on feeling well independently of what obstetric markers might tell. Both Tina and midwife Julia emphasize that they do not do away with "screening" or "checking." They assert that obstetrical surveillance is an important ingredient of homebirth care, by, paradoxically, simultaneously separating it from and inserting it into the larger picture of homebirth attendance.

Monitoring gets separated from homebirth care by becoming articulated with a "specialist field" and with "worries," and it is inserted into care, becoming one of many interventions within the homebirth midwifery repertoire and the monitoring of obstetric markers that is delegated to the midwife. The midwife-led birthplaces that I observed and the procedures of prenatal care visits that took place mostly in these places, indicate ambiguous ways of handling devices and interventions that also belong to obstetrics. Obstetrical devices are kept apart, but they are also introduced in self-evident and incidental ways. These birthplaces are warmly colored rooms with carpets, curtains, cozy couches and beds, wooden cupboards and tables, plants and candles. They are not arranged in accordance with practical or hygienic criteria only, but evoke an atmosphere of comfort and personal privacy. They are rooms to live in: the famous gynecological chair often placed prominently in the middle of the rooms in ob-gyn practices is missing. Syringes and other frequently used utensils are hidden away in drawers.

The contact between women and midwives, especially at the beginning of visits, resembles more that of close friends than how patients and health care professionals interact. Midwives and women ${ }^{8}$ hug each other in greeting, saying things like "Good to see you. Come in. How are you?" The answers women give to that initial question are often elaborated, women working through their daily life in detail: how tired and moody they feel, how they wake up regularly in the middle of the night from the hiccups of the child in their belly, how they had a silly dispute with their partner about the stroller they wanted to buy, how they are desperately searching for a bigger flat.

These conversations continue throughout the visits, frequently turning into consultations and then again becoming mundane causeries. In the course of these chats, not only do midwives and women get to know each other but midwives also 'use' them to get what they call a "general impression" of how the woman feelstired, anxious, or relaxed-and her physical condition: her gain in weight, the

\footnotetext{
${ }^{8}$ I mostly attended prenatal care visits with women and the midwives alone. Only very rarely, partners, friends or children took part as well.
} 
growing of her belly, her back pain or swollen ankles. Prenatal screening tests ${ }^{9}$ are introduced in ways that are nearly unnoticeable (Akrich and Pasveer 2000:71): chatting does not need to stop to measure a woman's blood pressure. She can stay seated while Julia grabs the blood pressure monitor from one of the wooden shelves next to the couch. As she knows the procedure, there is no need to advise her to roll up her left sleeve so that Julia can strap the cuff around her upper arm. After a moment of silence in which Julia listens to the pulse and checks the monitor's dial, she comments: "120 to 85 . Everything is fine." Then she continues to inquire about the couple's last vacation.

Whenever blood pressure values are slightly higher than usual or higher for the first time, Julia reads them as the body's expression of the current events in women's lives, remarking: "No wonder that your blood pressure is high with all the things you have to deal with at the moment." As Julia gets to know the woman, she can articulate a high blood pressure reading with women's mundane troubles. Since high blood pressure does not have to become the object of medical treatment, it can be addressed along with all those other onerous affairs that need to be dealt with anyway. ${ }^{10}$ By placing screening interventions into a home-like environment, by making them part of the visit routines without singling them out, screening interventions get routinized. In this case, routinizing is a technique that makes surveilling practices fit into women's daily lives, letting obstetric markers become signs of more or less ordinary events. This creates a precarious and provisional coherence: as they are being related to the daily activities and concerns, obstetric markers and screening interventions become non-specialized and non-singular.

Not all surveilling practices are routinized, however. Differently from measuring blood pressure or body weight, feeling women's bellies in prenatal care requires the attention of both women and midwives to the intervention itself. In obstetrical terms, feeling a woman's belly is defined as abdominal palpation, carried out in order to determine the height of the uterus, fetal growth, and the amount of amniotic fluid, as well as the position of the fetus in the womb. In homebirth care, midwife Clara suggests, the practice allows palpation of both the woman's belly and the 'child-in-the-belly', and allows the two women to become familiar with each other:

If you attend women in the beginning, you can hardly approach them. This means you cannot feel a lot [when touching the belly]. As the pregnancy progresses and the woman gets more open, because she knows you better, the easier it gets to feel how the child lies in the belly. The more you get the feeling that women open themselves up to you and allow you to approach.

\footnotetext{
9 Those screening tests are mandatory elements of prenatal care visits and encompass taking blood samples, analyzing urine, measuring blood pressure, palpating the woman's belly, and listening to the child's heart.

${ }^{10}$ However, the situation changes if blood pressure is extraordinarily high the third time in three days, and the woman's urine contains proteins as well. Midwife Julia reads these as possible signs of a severe pregnancy disorder and sends the woman to the hospital where she gets continual surveillance and medical treatment. Monitoring then comes to the fore and obstetric markers become decisive. At that point "also doing those medical-specialist things" turns into the promise that as a midwife Julia knows when to act upon pathological processes, and that making sure that woman and child are well in obstetric or medical terms is also part of her work and the ideal of building trustworthy relations.
} 
Palpating becomes a midwifery technique by being multiplied into feeling. Feeling the woman's belly does not only serve to determine the child's growth and position but also to build up trust. Through feeling the belly, both midwife and woman turn towards each other and meet each other with mutual attentiveness and interest. Feeling 'more' or 'better' is an achievement that results from mutually engaging in the procedure. The different purposes and results of the feeling practice, surveilling and establishing trusting relations, do not exclude one another, but become mutually stabilizing. The midwife's and the woman's bodies, but also the midwife's and the child's bodies, get increasingly familiar with each other through touching and feeling, and becoming familiar authorizes a more detailed obstetrical examination of the child. When diagnosing is combined with getting to know each other, relating personally and intimately helps to do better diagnostics. Similar to what Tina explained, midwife Clara makes clear that both she and the woman she works with need to engage with the midwifery technique when she says: "the more open the woman gets, because she knows you better, the easier it gets to feels how the child lies in the belly." In multiplying, different goals and findings get aligned by means of amplifying one another.

Obstetrical procedures such as monitoring or diagnosing are interwoven with homebirth midwifery practices. In the midwifery techniques of routinizing and multiplying, monitoring and diagnosing are articulated with a wider set of goals, namely attending to events that are physical, emotional, and social.

\section{Co-responding Homebirth Bodies}

The bodies of midwives and pregnant women need to learn to "open themselves up" to each other, to the techniques that are mobilized, and to the surrounding that indicates intimacy. Their bodies learn to be receptive to the specific repertoire that is offered and they learn to respond to it adequately. The following excerpt from my field notes illustrates how bodies learn to co-respond in the procedure of feeling the woman's belly in prenatal care:

During her first prenatal care visit, midwife Lisa asks Angelique to uncover her belly and to lie down on the sofa. "I would like to feel the child [nach dem Kind tasten]," Lisa says, kneeling beside the couch. She puts both hands on Angelique's belly and remains in this position for quite a while. Tim, Angelique's partner, squats next to Lisa and stretches his head to observe her hands on Angelique's belly. Angelique lies still and straight, while Lisa starts to move her hands slowly, centimeter by centimeter. One hand rests while the other slides further. "The child's head is here and the back...there." She invites first Angelique and then Tim to touch as well. To do so, she puts her own hands on theirs to guide them. Yes, they could feel something, both say with surprise.

Both pregnant woman and midwife need to align their bodies in order to make feeling the woman's belly and the child-in-the-belly work. Angelique lies on her back and relaxes and Lisa gets close in a way that allows her to touch Angelique's 
belly with both hands. Midwife Lisa makes Angelique and Tim feel what she feels, thus acquainting them with her technique of feeling. Lisa's and Angelique's bodies learn to co-respond with the help of touching and feeling and with the help of the verbal cues Lisa gives.

Midwife Clara explains further:

It was our first real prenatal care visit today, the first time of seeing and touching Laura's belly, and being physical with that woman at all. I have to get more familiar with her. One can notice easily that we met only twice. It is really good that I can do the prenatal care visits regularly now so that I get a feeling for her and for her way of being physical. In prenatal care you get references of how the woman wants to be attended to during birth. Actually, in prenatal care we are working towards birth.

Becoming increasingly familiar with Laura allows midwife Clara's body to refine her skills of adjusting to Laura's body. Laura's body gets used to midwife Clara's touching and learns to co-respond to it. Laura's "way of being physical" does not merely get disclosed by "seeing and touching and being physical" with each other, however, but is also being shaped with the help of Clara's recurrent interventions, as well as through the particular attention and interest she directs towards Laura's body. When Clara gets "references of how the woman wants to be attended to during birth," the two women's bodies are enacted as co-responsive, which is what matters when they "are working towards birth," as Clara characterizes the aim of prenatal care visits in homebirth midwifery. Midwives' and women's bodies learning to become co-responsive is considered necessary for succeeding in giving birth in homelike environments, as homebirth bodies need to permit being guided during birth. That guidance is distributed across the midwife, the pregnant woman, other attendants, and the homebirth environment that favors certain positions and interventions and hinders others. ${ }^{11}$

Who or what is taking the lead shifts frequently in the course of homebirths. The story of Ruth's homebirth illustrates that those dynamics build on bodies' facility with co-responding. Ruth has given birth to three children at home, and all three births have been attended by midwife Agnes. I describe an interaction I observed between Ruth and Agnes in the following excerpt from my field notes:

It is late in the evening when I meet midwife Agnes at Ruth's home. Ruth called Agnes earlier to tell her that she was having contractions every ten minutes and they decided that Agnes and I should set off now. Agnes does not want to be helped when she carries three heavy bags as we enter the flat. We join Ruth in her bedroom, which is well prepared with different items on which to sit, lie, and stand: the bed, chairs, a mat, and a gymnastic ball. Agnes settles in one of the dark corners of the room. She unpacks some papers, her Doppler ultrasound, a pen, and even a small headlamp that she uses when writing. Ruth breathes lightly and moves her pelvis in circles. Ruth's partner

${ }^{11}$ For example, using certain medication to induce labor and soothe pain, and/or being assisted in giving birth with the help of a vacuum extractor or via cesarean section, is not possible at home or in (homelike) midwife-led birthing places, but only in the hospital. 
Paul serves us some tea and Agnes and Ruth chat about someone they both know in between Ruth's contractions. Ruth's breathing becomes heavier. "You do whatever is good for you. If we bother you, you send us out," Agnes remarks. Ruth walks in circles. During her contractions she puts her hands on Paul's shoulders and moves her hips. Agnes continues writing, now and then taking a glimpse of Ruth. "You are doing well. It is hard to recognize that you are about to give birth; you are all calm and concentrated." Then she picks up the Doppler and holds the transducer to Ruth's belly. We hear a slight throbbing. "It [the child] is all calm as if nothing happened. It is sleeping now."

Both Ruth and Agnes are familiar with the easy chatting as a technique that marks Agnes's presence. In this situation, the chatting routinizes Ruth's labor and Agnes's attendance, which also consists of surveilling, observing, and valuing Ruth's birthing body and her way of handling it. When listening to the heart sounds of the child-in-the-belly with the help of the Doppler fetal monitor, midwife Agnes multiplies the measuring of the child's heartbeat into connecting Ruth and the child: It is "all calm as if nothing happened," just like Ruth herself who is "all calm and concentrated." Similar to Tina's midwife, Julia, who emphasizes that if Tina feels well, then usually her child feels well too, Agnes guides Ruth in concentrating on herself and on her body, while Agnes checks on the child's well-being, suggesting that this is a good strategy for dealing with birth at that point. Ruth's body is enacted as a body that is able to co-respond to the undisturbed homebirth surrounding, to the techniques mobilized, and to Agnes' body. Exactly because Ruth's body has learned to be co-responsive, it is susceptible to our presence in a way that might affect the birthing process, which is now working well. Giving birth thereby becomes a physical but also emotional and social endeavor.

During the course of Ruth's birth, her body-in-labor (Akrich and Pasveer 2004:66) has to meet other expectations than in the beginning. Ruth's body position shifts: it needs to co-respond by allowing for being directed more actively by midwife Agnes towards giving birth. My field notes continue:

Ruth lies down on the bed next to Paul. Midwife Agnes and I sit on the floor and whisper next to them. Then Agnes approaches Ruth again, the Doppler in her hands. Ruth and Agnes take a short look at each other, and we listen to the child's heartbeat, inalterably calm and steady. After a while Agnes asks Ruth if she might do a vaginal examination in order to find out if the cervix has dilated further. Ruth nods and turns to lie on her back. While examining Agnes asks Ruth if she wanted to get a bath or a belly massage with an essential oil to augment labor. Ruth opts for the massage. Then she lies down on the bed, but gets up again after a short while: "What should I do?" Ruth continues standing and then sits down on the gymnastic ball. "You don't want to [give birth] yet, do you?" Agnes asks Ruth in a surprised tone. Ruth smiles tiredly, her eyes half closed: "Well..." Agnes insists: "You have to allow the child to come!" After a short silence Ruth asks Agnes to tell her if she has to change position. "We don't have to hurry, but you could alternately sit and stand." Agnes massages Ruth's lower back again and Ruth leans into Agnes's hands. 
Agnes listens to the child's heart again. "Can you feel that it is far down?" Ruth squats down, supported by Paul. Agnes, putting on her gloves, kneels in front of Ruth, looking at Ruth's vulva opening wide during the contraction. "Yes, you can do this! You can overcome the threshold! Very good!"

While it was important to find a rhythm of moving and breathing as strategies for staying "calm and concentrated" at the onset of giving birth, it is now important to give birth within a certain time span. As a result of the vaginal examination, ${ }^{12}$ in which Agnes feels that Ruth's cervix is fully dilated, Agnes concludes that augmenting labor is necessary in order to help the birthing process to proceed. She offers several guidance techniques to Ruth's body-in-labor and takes a leading role in directing it: Agnes proposes that Ruth alternates body postures in order to facilitate the descent of the child. While applying the oil to Ruth's belly aims at stimulating contractions, massaging Ruth's back is expected to relieve pain. Both procedures also imply feeling as a means to convey and detect intimacy and trust. Agnes continues to enact Ruth's body as a body that has learned to co-respond, that can follow the guidance she procures. When taking the lead, Agnes does not exclude Ruth but invites her to continue to take part while also acknowledging her hesitation and fatigue ("We don't have to hurry."). However, Ruth's body struggles with coresponding to the techniques aimed at accelerating birth. Ruth tries to collaborate but she is in pain and exhausted and thus not readily available to the attending techniques. In response, Agnes invites Ruth to engage with Agnes's efforts by facilitating Ruth's motivation ("Can you feel that it [the child] is far down?") and through encouraging Ruth's "wanting" and actively "allowing the child to come" by letting her body-in-labor keep going. Both Ruth and Agnes know that if Ruth's body does not co-respond to the "gentle" ways of stimulating labor, as Agnes and her colleagues call it, Ruth will have to be transferred to the hospital. This, however, does not become necessary, as Ruth and Agnes manage to co-respond in this environment:

Agnes: "Ruth, do you want to walk a bit? Was this most effective? What's making you hesitate? You seemed close to falling asleep now." Ruth: "Yes, that is exactly how I feel." During the next contraction, Agnes puts two fingers in Ruth's vagina, and presses softly downwards. "Yes. Push in that direction. Your child wants to come out now! You can do this!" Squatting in front of Ruth, Agnes and I can see the child's head appearing between Ruth's labia. In between the contractions, Ruth closes her eyes and lets her head fall. Agnes, however, is strained. She does not take her eyes off of Ruth, encouraging her from the very beginning of every contraction. After three more contractions, the child is born. Agnes wraps the child in the towels that Paul has warmed in the oven and grabs her delivery instruments in order to clamp and cut the child's cord.

\footnotetext{
${ }^{12}$ The vaginal examination during birth serves to determine the opening of the cervix and the child's position. Birth progresses if the cervix opens up continually and the child descends progressively. Contractions that are sufficiently frequent and powerful make that happen.
} 
Through Ruth's birthing story, I have demonstrated how, in the process of coresponding, a mutual and embodied engagement in learning to skillfully respond to the midwifery techniques is foregrounded. The intimacy and trust that are established in the course of becoming acquainted with one another, with the techniques mobilized, and with the home environment are crucial for making the midwifery attending techniques work. Similarly, in the attendance of Lisa's birth, techniques of routinizing and multiplying surveilling interventions are employed in order to allow her homebirth body to co-respond and to give birth in these surroundings.

Lisa is accompanied by her family when she arrives at the birthing center on this late Friday afternoon. As Anna, her colleague, and I are still busy with taking care of Mira, who had just given birth an hour ago, we ask Lisa and her family to make themselves comfortable in the second birthing room. When Anna and I enter the room twenty minutes later, Lisa's mother is sitting at the table knitting. Next to her sits Lisa's sister, with Lisa's eldest child on her lap reading a story aloud. Lisa and her partner stand next to the chest of drawers which is the perfect height for Lisa to lean on during her contractions. She is breathing deeply and silently, moving her hips from one side to the other. "Is everything ok?" asks Anna. "Yes." Lisa looks up once the contraction is over. "Do you want to take a bath?" Anna asks. Lisa shrugs her shoulders: "Now? I don't know..." Anna: "Should we take a look at the cervix?" Lisa: "Yes!" During the next contraction Lisa cannot talk anymore. She closes her eyes and continues breathing deeply. Anna: "That is already in full swing." "Yes, I think so, too." Lisa sighs with a smile. Anna asks if Lisa wants her family to leave the room while she makes the vaginal exam. As they are leaving the room, Lisa lies down on the cot. Anna sits next to her and leans between Lisa's legs. "Please spread your legs a bit more. I have warm fingers and I will be very careful. Now I am taking a second finger." Anna hunches forward a bit further. "The child's head is already far down. The cervix is dilated to seven centimeters" Anna says contentedly, pulling back her fingers. "So it is in full swing! I will run the water in the bathtub!" Anna turns to lie on her side during the next contraction. Lisa waits for the contraction to cease: "How do you want this? Who is going to stay? I just had the impression that it was a bit difficult with everyone around." Lisa looks at Anna. "Yes, they have nothing to do. I will talk to them." Anna: "Ok. So you can get up or do whatever you want. But now that you are lying down, I will quickly listen to the child's heartbeat."

Midwife Anna uses several techniques to routinize her surveilling interventions during Lisa's birth. Firstly, she emphasizes the "impressions" she gets from being with and observing Lisa. Based on her impression on how Lisa breathes and moves, Anna identifies that the birth is "in full swing," which means that Lisa's contractions are efficient and that the child will probably be born soon. The vaginal examination that Anna proposes, and to which Lisa agrees, only confirms Anna's and also Lisa's opinions on the progress and stage of birth. It is neither the most important nor the only source of information. The examination is proposed only 
after the bath, suggesting that it is not the most urgent intervention, but one of several ways to proceed. Furthermore, Anna invites Lisa to become acquainted with the vaginal examination that she carries out. She offers suggestions for how Lisa will experience the examination, namely as comforting: Lisa will be touched carefully and with warm fingers. The midwife also shares the obstetric markers with Lisa, apparently in order to concretize what the birth being "in full swing" signifies in obstetric terms. Anna thus signalizes what also matters in homebirth environments: that how women and midwives evaluate the birthing body matches with surveilling parameters. Routinizing is done by privileging interventions that aim to keep up with Lisa's birthing body through creating situations that are deemed not to disturb or to interrupt its activities, but to support it in its "swing."

Lisa is offered to take a bath in order to create a situation that would allow her to give birth soon. In this situation, the bath does not offer a mere possibility for soothing labor pains, but it allows the creation of undisturbed and intimate surroundings. Lisa's family seemed busy with knitting and reading stories, but as Lisa pointed out, actually "they have nothing to do" besides waiting for the child to be born. Anna refers to the pressure that this waiting might exert on Lisa, when she shares her impression "that it was a bit difficult with everyone around." In this situation, water birth is multiplied into a midwifery technique that aims to facilitate birth through not only relieving pain and maintaining contractions within an individual and bounded body, but also by arranging an intimate environment in which Lisa - and certainly also midwife Anna-have fewer 'exterior' expectations to meet and may thus concentrate more easily on Lisa's body giving birth.

Ten minutes later, Lisa, her partner, and her sister enter the bathroom that Anna and I have quickly prepared. Sitting in the tub, Lisa breathes quite fast during her contractions, that have obviously become stronger. "You are doing great! Try to breathe a bit slower" Anna advises. And when the contraction is over she asks: "That contraction surprised you, didn't it?" Lisa: "These were the first explosive pains, I think. But I have the feeling that it does not fit yet." Anna: "Then you still have one or two contractions to get used to it. Your baby needs to be patient. Make some space! Very good!" After three more contractions, the baby's head is visible between Anna's labia, also in the pauses between contractions. Anna guides Lisa's hand to the baby's head. "You can touch it, then it might dare to come." In the next contraction, the child's head is born. "That is great! Perfect! Yes! Let your back fall. Leave some space! Super! Ok, now just press a tiny bit." After two more contractions, the child is born.

During Lisa's birth, the co-respondance between Lisa and midwife Anna is repeatedly enacted through Anna sharing her impressions of Lisa and her birthing body, as well as Lisa sharing and confirming these impressions. It is obvious, for example, that Lisa is not particularly keen on taking a bath at first, and however she understands and co-supports the aim of the intervention. Lisa shares her worries that the expulsive pains "do not fit yet," that she is not yet ready to give birth. In response, Anna grants Lisa more time and guides her through the last contractions: "Make some space" and "Now just press a tiny bit." As Anna co-responds to Lisa's 
bodily and verbally expressed needs, and as Lisa manages to follow Anna's interventions and to trust that they are helpful, giving birth in this homelike surrounding works well.

\section{Conclusion: Enacting Homebirth Bodies}

In this study, I asked what techniques midwives use in homebirth practices, and which versions of bodies emerge from these practices. In midwifery attendance techniques, several knowledge and skill repertoires are combined in order to configure pregnancies and births as physical, emotional, and social becomings. Quite some efforts are invested into rendering coherent the different approaches in homebirth attendance. As important ingredients of homebirth practices, interventions and devices that overlap with those used in obstetric surroundings get backgrounded. They become midwifery techniques through being routinized and multiplied in order to foreground what matters here: learning to co-respond to each other, to the attendance techniques, and to the homebirth environment. This is made possible not only by midwives assuming responsibility for surveilling and acting upon obstetric parameters but also by women collaborating through handing certain responsibilities over to the midwife and engaging with the attendance techniques offered. Midwifery techniques are used to align women's and midwives' bodies. Homebirth bodies are not enacted as stable and bounded, but are granted capacities of incorporating what is offered to them, of allowing themselves to be guided. I showed that during birth at home, coresponding bodies become prominent in order to make birth in that environment work.

To conclude my analysis of homebirth practices in Germany, I use two insights I borrow from a 'technological' strand of the anthropological research of reproduction as a "looking glass" (Franklin 2017) that helps us to see a more differentiated and situated picture than that provided by the earlier introduced 'sociocultural' strand, in which homebirth has been traditionally located and studied.

I showed that obstetrics and midwifery are not respectively monolithic fields, each determined by its own philosophy, its own body of knowledge, and its own way of engaging with pregnancies and births (Rooks 1999:370; Davis-Floyd 2018:323-38), despite what the German Association for Midwives and the sociocultural strand in anthropology argue. Instead, attending to the specificities of midwifery and obstetric practices reveals that they are deeply entangled. When describing homebirth practices, I argue that they differ and overlap in terms of what apparently similar procedures conducted in midwifery or obstetric environments such as measuring blood pressure or palpating women's bellies become, what concerns they attend to, which knowledge they mobilize, and which versions of bodies they bring to matter. Different knowledge repertoires can be combined synergistically, for example when 'becoming familiar' makes a more thorough physical examination possible. But as obstetric knowledge is frequently 
backgrounded during prenatal care, it might create ambiguities when it becomes decisive during pregnancy and birth.

This analysis avoids predefining and generalizing that female bodies are either 'natural', knowing, and sufficient or 'technological' and fallible. Instead of pinning down the 'natural,' often synonymous with 'biological' or 'physiological,' onto women's bodies ${ }^{13}$ (Macdonald 2006:239), ${ }^{14}$ I propose paying attention to the practicalities, the sociomaterial conditions under which particular versions of bodies emerge. Bodies are cultivated (Mol 2013:379): they need to gain specific skills in order to fit in homebirth practices, especially that of allowing to be guided, which includes being objectified occasionally. ${ }^{15}$ Different versions of homebirth bodies are sometimes difficult to combine, which creates ambiguities. Those ambiguities become especially prominent if the body has to live up to obstetric standards while also being trained to gain a certain independence from obstetric markers.

In material semiotics, classical nature-culture distinctions have been shown to be "politics by other means" (Haraway 1984:490; 1991) ${ }^{16}$ : they serve to yield and privilege certain realities while driving back others. Discourses that limit homebirth practices to the natural and non-interventional risk narrowing down the possibilities of being pregnant and giving birth but also the diversity of ways of attending to women and children in pregnancy and birth. Instead it is worth to follow them in detail in order to show how and with which aims midwives and women invest in those long-term engagements that are specific to homebirth surroundings but that could also inform clinical practices.

Acknowledgements I would like to thank the midwives and women who generously shared their work and lives with me. Thank you to my supervisors Jeannette Pols and Kristine Krause for providing such inspiring and caring support. I am also grateful to the reviewers at Culture, Medicine, and Psychiatry, whose comments helped to refine my arguments.

\footnotetext{
13 For that insight, I also draw on works from feminist scholars who argue that re-establishing naturally capable or naturally inept bodies contributes to silencing and subjugating any differences and similarities in and across bodies and worlds. See for example Haraway (1991), Grosz (1995), and Butler (1999).

14 Following political scientist Anne Phillips (2010:57), I think that socially constructed essentialism is "at its most overtly normative." Exactly because the category "natural' is a social construct it is possible to dismiss those who do not fulfill the criteria of disposing of a 'natural' body from that category. Introducing natural birthing bodies as a particular set of gender expectations compromising: "that women's bodies are naturally competent; that with proper support women can handle the pain of labor and even find it empowering; and that women can trust their gut feelings in a context in which choice is paramount, interventions are negotiable, and trust characterizes the midwife-client relationship" (Macdonald 2006:251) thus risks creating exclusive effects.

15 Assuming instrumental or objectified handling of the woman's body to be bad or problematic and its integration as an active agent to be good or productive may prove insufficient. How women configure their bodies and certain (potentially or de facto) objectifying procedures and devices may also depend on the outcomes of those procedures, which means they change over time, as Charis Thompson (2005:184-92) argues for women undergoing (and actively participating into) in vitro fertilization treatment.
}

16 The original and much-cited quote "science is politics by other means" derives from Bruno Latour's (1988) book The Pasteurization of France. 
Funding This study was funded by the Studienstiftung des deutschen Volkes.

\section{Compliance with Ethical Standards}

Conflict of interest The author, Annekatrin Skeide, declares that no conflict of interest exists.

Ethical Approval All procedures performed in studies involving human participants were in accordance with the ethical standards of the institutional and/or national research committee and with the 1964 Helsinki declaration and its later amendments or comparable ethical standards.

Informed Consent Informed consent was obtained from all interviewees. All names have been changed to pseudonyms and identifying information has been omitted.

Open Access This article is distributed under the terms of the Creative Commons Attribution 4.0 International License (http://creativecommons.org/licenses/by/4.0/), which permits unrestricted use, distribution, and reproduction in any medium, provided you give appropriate credit to the original author(s) and the source, provide a link to the Creative Commons license, and indicate if changes were made.

\section{References}

Akrich, Madeleine, and Bernike Pasveer

2000 Multiplying Obstetrics: Techniques of Surveillance and Forms of Coordination. Theoretical Medicine and Bioethics 21(1):63-83. https://doi.org/10.1023/A:1009943017769.

2004 Embodiment and Disembodiment in Childbirth Narratives. Body \& Society 10(2-3):63-84. https://doi.org/10.1177/1357034X04042935.

Aune, Ingvild, Mari A. Hoston, Nora J. Kolshus, and Christel E. G. Larsen

2017 Nature Works Best When Allowed to Run Its Course. The Experience of Midwives Promoting Normal Births in a Home Birth Setting. Midwifery 50(July):21-26. https://doi.org/10.1016/ j.midw.2017.03.020.

Barker, K.K.

1998 A Ship Upon a Stormy Sea: The Medicalization of Pregnancy. Social Science \& Medicine 47(8):1067-1076. https://doi.org/10.1016/S0277-9536(98)00155-5.

Butler, Judith

1999 Gender Trouble: Feminism and the Subversion of Identity. New York: Routledge.

Chadwick, Rachelle

2018 Bodies That Birth: Vitalizing Birth Politics. Women and Psychology. New York: Routledge.

Cheyney, Melissa

2011 Reinscribing the Birthing Body: Homebirth as Ritual Performance. Medical Anthropology Quarterly 25(4):519-542.

2008 Homebirth as Systems-Challenging Praxis: Knowledge, Power, and Intimacy in the Birthplace. Qualitative Health Research 18(2):254-267. https://doi.org/10.1177/1049732307312393.

Culley, Lorraine, and Nicky Hudson

2009 Marginalized Reproduction: Ethnicity, Infertility and Reproductive Technologies. London: Earthscan.

Davis-Floyd, Robbie

1992 Birth as an American Rite of Passage. Comparative Studies of Health Systems and Medical Care. Berkeley: University of California Press.

1994 The Technocratic Body: American Childbirth as Cultural Expression. Social Science and Medicine 38(8):1125-1140. https://doi.org/10.1016/0277-9536(94)90228-3.

2018 Ways of Knowing About Birth: Mothers, Midwives, Medicine, and Birth Activism. Long Grove: Waveland Press. 
Davis-Floyd, Robbie, and E. Davis

1996 Intuition as Authoritative Knowledge in Midwifery and Homebirth. Medical Anthropology Quarterly 10(2):237-269. https://doi.org/10.2307/649330.

Davis-Floyd, Robbie, and Carolyn Fishel Sargent

1997 Childbirth and Authoritative Knowledge: Cross-Cultural Perspectives. Berkeley: University of California Press.

Deutscher Hebammenverband (DHV)

2014 Standpunkt des Deutschen Hebammenverband e.V. zur Haftpflichtsituation im Bereich der freiberuflichen Hebammentätigkeit. Retrieved November 23, 2018 from https://www. hebammenverband.de/verband/berufspolitik/verband-und-berufspolitik/.

de Kok, Bregje, Julia Hussein, and Patricia Jeffery

2010 Joining-up Thinking: Loss in Childbearing from Inter-disciplinary Perspectives. Social Science \& Medicine 71(10):1703-1710. https://doi.org/10.1016/j.socscimed.2010.08.021.

De Vries, Raymond, Sirpa Wrede, Edwin van Teijlingen, and Cecilia Benoit, eds.

2001 Birth by Design: Pregnancy, Maternity Care, and Midwifery in North America and Europe. New York: Routledge.

Driessen, Annelieke

2017 Sociomaterial Will-Work: Aligning Daily Wanting in Dutch Dementia Care. In Care in Healthcare: Reflections on Theory and Practice. Franziska Krause and Joachim Boldt, eds., pp. 111-133. Palgrave Macmillan. https://doi.org/10.1007/978-3-319-61291-1.

Franklin, Sarah

2013 Biological Relatives: IVF, Stem Cells and the Future of Kinship. Durham: Duke University Press.

2017 Conception through a Looking Glass: The Paradox of IVF. Reproductive BioMedicine Online 27(6):747-755. https://doi.org/10.1016/j.rbmo.2013.08.010.

Gesellschaft für Qualität in der außerklinischen Geburtshilfe (QUAG)

2016 Außerklinische Geburtshilfe in Deutschland-Qualitätsbericht 2015. Retrieved November 23, 2018 from http://www.quag.de/quag/publikationen.htm.

Gesetz über den Beruf der Hebamme und des Entbindungspflegers (Hebammengesetz-HebG)

2016 [1985]. Retrieved November 23, 2018 from https://www.gesetze-im-internet.de/hebg_1985/.

Grosz, Elisabeth

1995 Space, Time and Perversion. Essays on the Politics of Bodies. New York: Routledge.

Haraway, Donna J.

1984 Primatology Is Politics by Other Means. In PSA: Proceedings of the Biennial Meeting of the Philosophy of Science Association 1984, Philosophy of Science Association, University of Chicago Press, Springer, pp. 489-524.

1991 Simians, Cyborgs, and Women: The Reinvention of Nature. London: Free Association Books.

Inhorn, Marcia C., and Daphna Birenbaum-Carmeli

2008 Assisted Reproductive Technologies and Culture Change. Annual Review of Anthropology 37(1):177-196. https://doi.org/10.1146/annurev.anthro.37.081407.085230.

Inhorn, Marcia C., Daphna Birenbaum-Carmeli, Soraya Tremayne, and Zeynep B. Gürtin

2017 Assisted Reproduction and Middle East Kinship: A Regional and Religious Comparison. Reproductive Biomedicine \& Society Online 4:41-51. https://doi.org/10.1016/ j.rbms.2017.06.003.

Jordan, Brigitte

1993 [1978] In Birth in Four Cultures: A Crosscultural Investigation of Childbirth in Yucatan, Holland, Sweden, and the United States. Robbie Davis-Floyd, ed., 4th ed. Prospect Heights, Ill: Waveland Press.

Kay, Margarita Artschwager

1982 Anthropology of Human Birth. Philadelphia: F.A. Davis.

Kitzinger, Sheila

1979 Birth at Home. Oxford: Oxford University Press.

2011 Rediscovering Birth. London: Pinter \& Martin.

Krebbekx, Willemijn

2018 Making Sex, Moving Difference: An Ethnography of Sexuality and Diversity in Dutch Schools. Unpublished Doctoral Dissertation. University of Amsterdam, Amsterdam, The Netherlands. 
Law, John, Geir Afdal, Kristin Asdal, Wen-yuan Lin, Ingunn Moser, and Vicky Singleton

2014 Modes of Syncretism: Notes on Noncoherence. Common Knowledge 20(1):172-192. https:// muse.jhu.edu/article/532902.

Latour, Bruno

1988 The Pasteurization of France. Cambridge: Harvard University Press.

M' Charek, Amade

2013 Beyond Fact or Fiction: On the Materiality of Race in Practice. Cultural Anthropology 28(3):420-442. https://doi.org/10.1111/cuan.12012.

MacCormack, Carol

1996 Birth in Four Cultures: A Cross-Cultural Investigation of Childbirth in Yucatan, Holland, Sweden, and the United States. 44th Ed. Brigitte Jordan (Revised and Expanded by Robbie Davis-Floyd). Medical Anthropology Quarterly 10(1):96-98. https://doi.org/ 10.1525/maq.1996.10.1.02a00110.

MacCormack, Carol, ed.

1982 Ethnography of Fertility and Birth. London: Academic Press.

Macdonald, Margaret

2006 Gender Expectations: Natural Bodies and Natural Births in the New Midwifery in Canada. Medical Anthropology Quarterly 20(2):235-256. https://doi.org/10.1525/maq.2006.20.2.235.

Marcus, George

1995 Ethnography in/of the World System: The Emergence of Multi-Sited Ethnography. Annual Review of Anthropology 24:95-117.

Mol, Annemarie

2014 Language Trails: 'Lekker' and Its Pleasures. Theory, Culture \& Society 31(2-3):93-119. https:// doi.org/10.1177/0263276413499190.

2002 The Body Multiple: Ontology in Medical Practice. Durham: Duke University Press.

2013 Mind Your Plate! The Ontonorms of Dutch Dieting. Social Studies of Science 43(3):379-396. https://doi.org/10.1177/0306312712456948.

Mol, Annemarie, Ingunn Moser, and Jeannette Pols

2010 Care: Putting Practice into Theory. In Care in Practice: On Tinkering in Clinics, Homes and Farms. Annemarie Mol, Ingunn Moser, and Jeannette Pols, eds., pp. 7-25. Bielefeld: Transcript Verlag.

Moser, Ingunn

2011 Dementia and the Limits to Life: Anthropological Sensibilities, STS Interferences, and Possibilities for Action in Care. Science, Technology, \& Human Values 36(5):704-722. https:// doi.org/10.1177/0162243910396349.

Naraindas, Harish

2011 Of Relics, Body Parts and Laser Beams: The German Heilpraktiker and His Ayurvedic Spa. Anthropology \& Medicine 18(1):67-86. https://doi.org/10.1080/13648470.2010.525873.

Newnham, Elizabeth, Lois McKellar, and Jan Pincombe

2018 Towards the Humanisation of Birth. A Study of Epidural Analgesia and Hospital Birth Culture: Palgrave Macmillan.

Oakley, Ann

1984 The Captured Womb: A History of the Medical Care of Pregnant Women. Oxford: Blackwell.

Organisation for Economic Co-operation and Development (OECD)

2018 OECD Data. Caesarean Sections (indicator). https://doi.org/10.1787/adc3c39f-en.

Pasveer, Bernike, and Madeleine Akrich

2001 Obstetrical Trajectories. On Training Women/Bodies for (Home)Birth. In Birth by Design. Pregnancy, Maternity Care and Midwifery in North America and Europe. De Vries, C. B. R., van Teijlingen, E. R., and S. Wrede, eds., pp. 229-242. New York: Routledge.

Petchesky, Rosalind Pollack

1987 Fetal Images: The Power of Visual Culture in the Politics of Reproduction. Feminist Studies 13(2):263-292. https://doi.org/10.2307/3177802.

Pols, Jeannette

2017 Good Relations with Technology: Empirical Ethics and Aesthetics in Care. Nursing Philosophy 18:1-7. https://doi.org/10.1111/nup.12154.

Ram, Kalpana, and Margaret Jolly, eds.

1998 Maternities and Modernities: Colonial and Postcolonial Experiences in Asia and the Pacific. Cambridge: Cambridge University Press. 
Rapp, Rayna

2000 Testing Women, Testing the Fetus: The Social Impact of Amniocentesis in America. The Anthropology of Everyday Life. New York: Routledge.

Rooks, J.P.

1999 The Midwifery Model of Care. Journal of Nurse-Midwifery 44(4):370-374. https://doi.org/ 10.1016/S0091-2182(99)00060-9.

Rothman, Barbara Katz

1982 In Labor: Women and Power in the Birthplace. New York: Norton.

2012 Where Are the Midwives? The American Journal of Bioethics 12(7):56-58. https://doi.org/ 10.1080/15265161.2012.680535.

Scarf, Vanessa, Chris Rossiter, Saraswathi Vedam, Hannah G. Dahlen, David Ellwood, Della Forster,

Maralyn J. Foureur, H. McLachlan, J. Oats, D. Sibbritt, and C. Thornton

2018 Maternal and Perinatal Outcomes by Planned Place of Birth among Women with Low-Risk Pregnancies in High-Income Countries: A Systematic Review and Meta-Analysis. Midwifery 62:240-255. https://doi.org/10.1016/j.midw.2018.03.024.

Simonds, Wendy, Barbara Katz Rothman, and Bari Meltzer Norman

2007 Laboring on: Birth in Transition in the United States. Perspectives on Gender. New York: Routledge.

Stone, Nancy I.

2012 Making Physiological Birth Possible: Birth at a Free-Standing Birth Centre in Berlin. Midwifery 28(5):568-575. https://doi.org/10.1016/j.midw.2012.04.005.

Strathern, Marilyn

1992 Reproducing the Future: Essays on Anthropology, Kinship and the New Reproductive Technologies. New York: Routledge.

1995 No Nature, No Culture: The Hagen Case. In Nature, Culture and Gender. Carol Pulley MacCormack and Marilyn Strathern, eds., pp. 174-222. Cambridge: Cambridge University Press.

Thompson, Charis

2005 Making Parents: The Ontological Choreography of Reproductive Technologies. Inside Technology. Cambridge: MIT Press.

Vogel, Else

2017 Hungers That Need Feeding: On the Normativity of Mindful Nourishment. Anthropology \& Medicine 24(2):159-173. https://doi.org/10.1080/13648470.2016.1276322.

Weir, Lorna

2006 Pregnancy, Risk, and Biopolitics: On the Threshold of the Living Subject. Transformations: Thinking through Feminism. New York: Routledge. 